\title{
Chris Allen and Rob Imrie (eds): The knowledge business: the commodification of urban and housing research
}

\author{
Ashgate, Farnham, UK, and Burlington, VT, USA, 2010, \\ 283 pp, ISBN: 978-0-7546-7690-4
}

\section{Hugo Priemus}

Published online: 12 June 2012

(C) The Author(s) 2012. This article is published with open access at Springerlink.com

In recent decades, universities in many European countries, particularly the UK, have been chasing efficiency, market forces and external funding via contract research. Chris Allen and Rob Imrie see this as an unwelcome and possibly even harmful development: the critical capacity and the impartiality of academic urban and housing research are at stake. These convictions prompted them to edit and publish a collection of essays entitled 'The Knowledge Business: the commodification of urban and housing research' in 2010 (Ashgate).

The origins of this book lie in a series of ESRC seminars that sought to open up the knowledge business to scrutiny by drawing critical attention to the social relations in the production of contracted research in housing and urban studies. Some of the papers that were presented at these seminars have been published as chapters in the book. The book offers a critique of the knowledge business. It describes and evaluates its different manifestations in, and impacts on the university sector. The chapters highlight the different ways in which the Academy is being set to work for commercial gain, and evaluate how far the public service ethos of the universities is unravelling in a context in which this service is increasingly defined by the 'ability to pay' of a private clientele.

Contributions are presented by Gary Bridge, Noel Castree, Jon Coaffee, Vickie Cooper, David Demeritt, Marian Hawkesworth, Jim Kemeny, Loretta Lees, Tony Manzi, Pauline Marne, Paul O'Hare, Gilles Pinson, William Smith-Bowers and Huw Thomas.

The book examines the growing interaction between theory and practice, and policy and science. The tone is concerned and occasionally even whingeing. According to most of the authors, the pursuit of knowledge valorisation, more effective policy and enhanced prosperity are at odds with independent and critical research. Efficiency drives and initiatives to raise productivity in academic research are suspect: the heading 'Universities: Measured, Monitored, Managed and Massified' (p. 227) speaks volumes. The authors distrust measurement of the quantity and quality of scientific research. They question the claim that 'knowledge is useful and measurable' and greet the British Research Assessment Exercises (RAE) with scepticism. In the eyes of the authors, the time registration requirement in the

H. Priemus $(\bowtie)$

TU Delft, Delft, The Netherlands

e-mail: h.priemus@tudelft.nl 
national Time Allocation Surveys (TAS) is an abomination. They shrug off the individualised, institution-wide Research Profiling Exercise currently underway in Manchester with: 'Overwhelmingly, British Universities' current audit culture is a product of central government diktat' (p. 229).

All the contributors are British except two (Jim Kemeny is Swedish and Gilles Pinson is French). Thus, the book conveys an impression of 'all pals together'. The authors display no awareness of the potential benefits of better accountability among researchers and more interaction between research and policy on the one hand, and theory and practice on the other. They make no pronouncements on whether research has generally improved or deteriorated in recent decades. They do not say whether the RAEs-which have been carried out for years-have led to high rankings for the wrong researchers: the most amenable or the most law-abiding. I would be more inclined to hold up the RAE in the UK as an example to other countries. Scarcely any alternatives are suggested. Castree (p. 221-240) does formulate ten proposals for change at the end of the book, but it is open to question whether these are realistic or bring us any further.

The book, edited by Chris Allen and Rob Imrie, discusses a phenomenon that is manifesting itself in many countries, but strongly in the United Kingdom. The general tenor of the essays is - in my opinion-biased and testifies to a simplistic approach to science and research: university researchers are the only people who have got it right and they should be exposed as little as possible to influences from policy and practice. That applies a fortiori to the funding of research by policy institutes and organisations in the field. Let us hope that many people read this book by Allen and Imrie and are encouraged to develop other visions of the relationship between theory, policy and practice in urban and housing research.

Open Access This article is distributed under the terms of the Creative Commons Attribution License which permits any use, distribution, and reproduction in any medium, provided the original author(s) and the source are credited. 